\title{
Self-management of pain among people who inject drugs in Vancouver
}

\author{
Pauline Voon ${ }^{1}$, Cody Callon ${ }^{1}$, Paul Nguyen ${ }^{1}$, Sabina Dobrer ${ }^{1}$, Julio Montaner ${ }^{1,2}$, Evan \\ Wood $^{1,2}$, and Thomas Kerr ${ }^{1,2,{ }^{*}}$ \\ ${ }^{1}$ British Columbia Centre for Excellence in HIV/AIDS, St Paul's Hospital, 608-1081 Burrard Street, \\ Vancouver, BC, V6Z 1Y6, Canada \\ ${ }^{2}$ Department of Medicine, University of British Columbia, St Paul's Hospital, 608-1081 Burrard \\ Street, Vancouver, BC, V6Z 1Y6, Canada
}

\section{SUMMARY}

\begin{abstract}
Aims-To evaluate factors and methods associated with self-management of pain among people who inject drugs (IDUs) in Vancouver (Canada).

Patients \& methods-This cross-sectional study used bivariate statistics and multivariate logistic regression to analyze self-reported responses among 483 IDUs reporting moderate-toextreme pain in two prospective cohort studies from 1 December 2012 to 31 May 2013.
\end{abstract}

\begin{abstract}
Results-Median age was 49.6 years (interquartile range: $43.9-54.6$ years), 33.1\% of IDUs were female and $97.5 \%$ reported self-management of pain. Variables independently and positively associated with self-managed pain included having been refused a prescription for pain medication (adjusted odds ratio: 7.83; 95\% CI: 1.64-37.3) and having ever been homeless (adjusted odds ratio: 3.70; 95\% CI: 1.00-13.7). Common methods of self-management of pain included injecting heroin (52.7\%) and obtaining diverted prescription pain medication from the street (65.0\%).

Conclusion-Self-management of pain was common among IDUs who reported moderate-toextreme pain in this setting, particularly among those who had been refused a prescription for pain medication and those who had ever been homeless. These data highlight the challenges of adequate pain management among IDUs.
\end{abstract}

Injection drug use is associated with a host of health-related illnesses and harms, which are often a source of physical pain that can result in significantly reduced quality of life and decreased levels of function [1-3]. Appropriate pain management of people who inject drugs (IDUs) can play an important role in improving quality of life, decreasing lengths of hospital stays, reducing the frequency of readmission for patients who self-discharge from hospital

\footnotetext{
(C) 2014 Future Medicine Ltd

*Author for correspondence: Tel.: +1 604806 9116; Fax: +1 604806 9044; uhri-tk@cfenet.ubc.ca.

For reprint orders, please contact: reprints@ futuremedicine.com

Ethical conduct of research

The authors state that they have obtained appropriate institutional review board approval or have followed the principles outlined in the Declaration of Helsinki for all human or animal experimental investigations. In addition, for investigations involving human subjects, informed consent has been obtained from the participants involved.

Financial \& competing interests disclosure

The study was supported by the US NIH (R01DA011591 and R01DA021525). This research was undertaken, in part, thanks to funding from the Canada Research Chairs program through a Tier 1 Canada Research Chair in Inner City Medicine which supports Dr Evan Wood. The authors have no other relevant affiliations or financial involvement with any organization or entity with a financial interest in or financial conflict with the subject matter or materials discussed in the manuscript apart from those disclosed.

No writing assistance was utilized in the production of this manuscript.
} 
against medical advice and increasing patient confidence in the medical system, thereby enhancing the potential for successful treatment of addiction [4,5].

However, pain among IDUs has many possible etiologies and contributors that pose substantial challenges for patients and clinicians. For instance, pain among IDUs may be caused by illnesses or injuries that are either acute (e.g., trauma and local infections) or chronic (e.g., HIV, hepatitis $\mathrm{C}$ and chronic venous insufficiency); drug withdrawal (which increases pain response, decreases pain tolerance and may be associated with painful symptoms, such as abdominal cramps, myalgias or bone pain); or psychiatric (e.g., affective disorders, such as depression or anxiety that may create a more severe pain experience) [24]. In many instances, such sources of pain may have been caused by the harms associated with injection drug use in the first place, such as cellulitis and soft tissue infections from injection using unsanitary syringes, or HIV/HCV infection from injection using contaminated syringes [6-8]. Furthermore, some individuals with long-term opioid dependence may have developed lower pain thresholds and reduced tolerance for pain [9].

Additionally, pain is difficult to objectively assess and treat in the clinical setting because it may be manifested uniquely in each individual as a subjective emotion, sensation or experience $[4,10]$, as described by the International Association for the Study of Pain, which defines pain as "an unpleasant sensory and emotional experience associated with actual or potential tissue damage, or described in terms of such damage" [101]. Furthermore, clinicians often lack clear evidence-based guidelines for prescribing analgesia among patients with a history of addiction or substance use [10], despite the existence of related basic management principles and guidelines in the literature [11-14]. As a result, IDUs are significantly more likely to receive inadequate pain relief [1]. Concerns that inhibit physicians' willingness to prescribe analgesia to drug users include the potential risks for dependence, misuse or diversion [10,15]. In particular, clinical guidelines of the American Pain Society and the American Academy of Pain Medicine warn that the potential risks of misuse, abuse and addiction may warrant restrictions on prescribing opioids outside of specialized and controlled settings for some patients with a history of substance abuse [14]. Additionally, clinicians may misinterpret requests for pain medication from an IDU as 'drug-seeking' $[2,16]$. All of these factors may contribute to the undertreatment of pain among IDUs. Consequently, IDUs often feel stigmatized or mistreated $[2,16,17]$ and may resort to self-managing their pain.

While a limited body of literature has documented the perspectives of drug users who struggle with clinical pain management $[1,16]$, little is known about the frequency of and strategies for self-management of pain among IDUs. Therefore, we sought to investigate the prevalence, correlates and methods of self-managed pain among a community-recruited cohort of IDUs in Vancouver (Canada).

\section{Methods}

\section{Subjects}

Beginning in May 1996, persons who had injected illicit drugs at least once in the previous month and resided in the Greater Vancouver region were recruited into one of two ongoing prospective observational cohorts: the AIDS Care Cohort to Evaluate Access to Survival Services (ACCESS) cohort of HIV-seropositive IDUs or the Vancouver Injection Drug Users Study (VIDUS) of HIV-seronegative IDUs. These cohorts have been described in detail previously [18-20]. In total, over 2500 subjects have been recruited through snowball sampling and extensive street outreach methods. Individuals were eligible for the studies if they were aged 18 years or older and provided written informed consent. At baseline and semi-annually, participants answered a standardized interviewer-administered questionnaire 
and provided blood samples for serologic analysis (among HIV-negative individuals) and disease monitoring (among HIV-positive individuals). At the end of each study visit, participants were provided with a monetary stipend of CAD $\$ 20$ and any necessary referrals for medical care, HIV/AIDS care or drug and alcohol treatment. Each questionnaire was scrutinized by at least two trained interviewers, and any logical inconsistencies resolved before being entered. The data entry program used to enter questionnaire data included data quality and verification checks, including field range limits and logical checks. Participants have been followed prospectively in this ongoing study with no defined end point. These studies have received ethics approval from the University of British Columbia (Vancouver, Canada) and Providence Health Care Office of Research Services (Vancouver, Canada).

\section{Measures}

The present analysis was restricted to interviews that took place during a single follow-up period from 1 December 2012 to 31 May 2013. We restricted our sample to active IDUs who reported moderate-to-extreme pain according to the standardized Euroqol EQ-5D health utility instrument, which has been shown to be a valid, responsive and reliable survey instrument among individuals with chronic pain and substance users [21-23]. In order to identify IDUs who have ever self-managed pain, the following question from the standardized interviewer-administered questionnaire was asked of all current injectors who reported moderate-to-extreme pain during this follow-up period: 'Have you ever managed your own pain?' Participants who responded 'No' (i.e., participants who reported having never self-managed pain) were not asked any further questions regarding pain. Participants who responded 'Yes' (i.e., participants who reported having previously managed their own pain) were subsequently asked how they self-managed their pain through the question, 'If yes, how?' Participants were able to respond ad libitum to this question, with more than one response if desired.

We compared those who did and did not report self-management of pain to identify the factors associated with self-management of pain. The sociodemographic characteristics and other factors considered in the analyses were: age, gender, homelessness, unstable housing, residence in Vancouver's Downtown Eastside, education status, HIV status, sex work, incarceration, having a physical disability and having ever been refused pain medication. The latter variable was derived from the questions: 'Have you ever requested a prescription for pain medication?' then 'If yes, were you ever refused a prescription?' The variables related to drug use included: daily noninjection crack use, daily crystal meth injection, daily heroin injection, daily cocaine injection, daily marijuana use, heavy alcohol use, prescription opioid abuse, having ever enrolled in methadone maintenance treatment, having ever overdosed and binge injection drug use. Unless otherwise indicated, these sociodemographic and drug-using variables pertain to the previous 6 months prior to the time of interview. Heavy alcohol use was defined as an average of more than two drinks per day or more than 14 drinks per week over the past 6 months for males, or an average of more than one drink per day or more than seven drinks per week over the past 6 months for females [24-26]. Prescription opioid abuse was defined as the use of prescription opiates not as prescribed (e.g., exceeding the prescribed dose, injecting or crushing medications) or the use of prescription opiates not prescribed to the individual [27]. In order to capture overdoses resulting from various types of illicit drugs, including stimulants, the overdose variable was defined using a 'Yes' or 'No' response to the question, 'In the last 6 months, have you overdosed by accident (i.e., where you had an unexpected negative reaction from using too much drugs)?' Finally, binge injection drug use was defined as periods of time during which drugs were injected more frequently than usual, as per the definition of bingeing in previous studies $[28,29]$. 


\section{Statistical analysis}

Using these variables, we analyzed which factors were associated with self-management of pain using bivariate statistics and multivariate logistic regression analyses. Categorical variables were analyzed using Pearson's $\chi^{2}$ test and Fisher's exact test (when one or more cells contained values less than or equal to five), and continuous variables were analyzed using simple logistic regression. We then applied an a priori-defined statistical protocol based on examination of the Akaike information criterion (AIC) and p-values to construct an explanatory multivariate logistic regression model. First, we constructed a full model including variables that were significant at the level of $p \leq 0.1$ in the bivariate analyses. After noting the AIC of the model, we removed the variable with the largest p-value and built a reduced model. We continued this iterative process until no variables remained for inclusion. We selected the multivariate model with the best overall fit, as indicated by the lowest AIC score. The variables in the final model were assessed with variance inflation factors (VIFs) and condition indices to ensure the absence of collinearity. All p-values were two-sided.

\section{Results}

In total, 483 active IDUs reported moderate-to-extreme pain and were eligible for this analysis during a single follow-up period from 1 December 2012 to 31 May 2013. Of these, $323(66.9 \%)$ were men and $160(33.1 \%)$ were women, and 224 (46.4\%) were HIV-positive. The median age was 49.6 years (interquartile range: $43.9-54.6$ years). The median duration of follow-up in the study among participants in this analysis was 6.2 months (interquartile range: 1.9 months). In total, 471 (97.5\%) of active IDUs with moderate-to-extreme pain reported self-managed pain, while $12(2.5 \%)$ active IDUs with moderate-to-extreme pain did not report self-managed pain.

Table 1 shows the sociodemographic characteristics of the participants stratified by those who did and did not self-manage pain. As indicated, having been refused pain medication (odds ratio [OR]: 8.31; 95\% CI: $1.80-38.3 ; \mathrm{p}=0.007$ ) and having ever been homeless (OR: $4.41 ; 95 \%$ CI: $1.28-15.2 ; \mathrm{p}=0.019)$ were positively associated with self-management of pain. We found no significant associations between self-management of pain and age, gender, Downtown Eastside residence, unstable housing, education status, HIV serostatus, sex work, incarceration or physical disability.

Table 2 shows the bivariate analyses of variables related to drug use. We found no association between self-management of pain and daily noninjection crack use, daily crystal meth injection, daily heroin injection, daily cocaine injection, daily marijuana use, heavy alcohol use, prescription opioid abuse, enrollment in methadone maintenance treatment, overdose or binge injection drug use.

The multivariate logistic regression analysis of factors independently associated with selfmanagement of pain is shown in Table 3. As shown here, having been refused a prescription for pain medication (adjusted OR [AOR]: 7.83; 95\% CI: $1.64-37.3 ; \mathrm{p}=0.010$ ) and having ever been homeless (AOR: $3.70 ; 95 \%$ CI: $1.00-13.7 ; \mathrm{p}=0.050$ ) remained positively associated with self-managed pain.

The self-reported methods of self-managing pain are shown in Table 4. As indicated, the most common methods of self-managing pain were injecting heroin (52.7\%) and obtaining diverted prescription pain medication from the street $(65.0 \%)$. The most commonly obtained pain medications from the street were morphine (43.3\%), hydromorphone (e.g., Dilaudid ${ }^{\circledR}$, Purdue Pharma, Ontario, Canada; 31.8\%), acetaminophen with codeine (e.g., Tylenol ${ }^{\circledR}$ with Codeine \#3, McNeil Consumer Healthcare, Ontario, Canada; 25.3\%) and acetaminophen 
with oxycodone (e.g., Percocet ${ }^{\circledR}$, Bristol-Myers Squibb Canada, Quebec, Canada; 13.8\%). These were also the most commonly reported pain medications that were obtained from a friend, partner or acquaintance; however, this method of obtaining diverted pain medication was less common $(25.1 \%)$. Other self-reported methods of self-managing pain included marijuana (21.4\%), cocaine (9.1\%), crack (8.7\%), alcohol (7.9\%) and over-the-counter medications such as ibuprofen (12.7\%) or acetaminophen (8.9\%). A small percentage of participants reported self-management of pain using complementary approaches such as heat $(10.2 \%)$, exercise $(8.3 \%)$, or rest or relaxation $(8.1 \%)$.

\section{Discussion}

In this study, we found that a large majority (97.5\%) of the recruited active IDUs who reported moderate-to-extreme pain had self-managed their pain within their lifetime. Variables independently and positively associated with self-managed pain included having been refused a prescription for pain medication and having ever been homeless. Pain was most frequently self-managed by injecting heroin or obtaining diverted prescription pain medication from the street.

The high proportion of IDUs that self-manage their pain in this study may be due to inadequate pain management approaches for substance users in the clinical setting, as has been previously described in the literature [30,31]. Much of the focus of the literature on pain management among drug users is on practitioners' experiences managing substance users' pain in clinical settings $[2,4,10,15]$. While previous literature has characterized pain among patients with a history of substance use in certain clinical settings such as methadone maintenance centers [32], to our knowledge, our study is the first to characterize selfmanagement of pain outside of a clinical setting among a community-recruited sample of IDUs.

Concerns regarding the diversion of pain medications are a key reason why practitioners are often reluctant to prescribe pain medication in the clinical setting [10,15,17]. However, our findings show a strong association between being denied a prescription for pain medication and self-management of pain. This suggests that after being denied pain relief in the clinical setting, IDUs often resort to self-managing their pain using high-risk methods, such as injection drug use or obtaining diverted pain medication within street-based drug markets. While current clinical guidelines of the American Pain Society and the American Academy of Pain Medicine warn that the potential risks of misuse, abuse and addiction may outweigh the benefit of opioid therapy in some patients with a history of substance abuse [14], our findings suggest that clinicians who deny pain medication to those who require it may be inadvertently fuelling the demand for diverted pharmaceuticals. Therefore, further research is needed to develop and evaluate strategies that may facilitate appropriate pain treatment, while limiting the potential for misuse, abuse, addiction or diversion, such as directly observed therapy in controlled and specialized opioid treatment programs [14], tamperresistant formulations that deter opioid misuse [33], frequent urine drug screen monitoring at primary care clinics [34] or complementary and alternative therapies for injection drug users [35].

We found that IDUs who had ever been homeless were more likely to self-manage their pain. Previous studies of pain management among homeless individuals experiencing pain reveal that acute or chronic pain may be common among homeless populations owing to a high frequency of injuries and high prevalence of comorbidities [36,37]. Furthermore, prior studies demonstrate that perceived barriers to pain management among homeless populations include unstable and stressful living environments, poor sleeping conditions, the inability to afford prescription medications, being offered only over-the-counter pain 
medication or perceived inadequate pain assessments by physicians [36-39]. As a result, similar to our findings, homeless participants in other studies have reported self-medication for pain using over-the-counter or prescription medications, illicit drugs or alcohol [37,38]. Therefore, further strategies are needed to promote effective pain assessment and management for homeless patients with limited or unstable resources.

In this study, the most common method of self-managing pain was injecting heroin. While the pain-relieving properties of heroin as an opiate analgesic are well documented, illicit heroin injection for pain is concerning because of the associated risks such as overdose, complications that may further perpetuate the individual's pain (e.g., localized and systemic infections, and infectious disease transmission), and the potential for worsening addiction [40-42]. Indeed, injecting heroin for pain may inhibit efforts to cease injecting or reduce opiate use when continued injection drug use for pain management occurs. While prescription opioids also pose potential for dependence or addiction, close monitoring of opioid analgesia in controlled and specialized settings may promote therapeutic dosing while avoiding additional risks associated with illicit heroin injection, including injection drug use and immersion within illicit drug markets [14].

The second most prevalent method of self-managing pain in this study was obtaining diverted prescription pain medication off the street, particularly morphine, hydromorphone (e.g., Dilaudid), acetaminophen with codeine (e.g., Tylenol with Codeine \#3) and acetaminophen with oxycodone (e.g., Percocet). This is consistent with the literature on diverted prescription medications, which has consistently found that opioid analgesics are the most popular diverted medications [43-48]. As demonstrated by an assessment of prescription drug user focus groups [46], individuals may prefer to use diverted pain medications due to the perception that these drugs are less stigmatizing, less dangerous and less subject to legal consequences compared with illicit drugs. On the contrary, the use of diverted pain medication is extremely dangerous as it poses high risks for overdose and toxicity since its administration cannot be monitored for dosing, integrity of ingredients, polydrug interactions or adverse effects that may result in addiction, overdose or death [48].

This study has several limitations. First, the cross-sectional design of the study limited our ability to determine a temporal relationship between the explanatory variables and the outcome. In particular, we were not able to assess antecedent drug use patterns that predicted self-management of pain, although our approach provides some insight into druguse patterns that may follow self-management of pain. Therefore, the associations noted in this study should be further examined through longitudinal analyses. Second, our study relied on self-reported data that is susceptible to reporting biases, such as socially desirable reporting and recall bias. Third, because the study was conducted in one city in Canada and included participants enrolled through snowball sampling and street outreach rather than random selection, the interpretation of these results may not be generalizable to other IDU populations. Finally, our analysis did not capture methods of pain management or the prevalence of diverted opioid use among IDUs who did not report self-managed pain, which should be considered in future studies.

\section{Conclusion \& future perspective}

Collectively, these findings indicate the need for improved pain management for IDUs in the clinical setting, as this may serve to reduce the prevalence of self-management of pain in ways that pose high risk for morbidity and mortality. Punitive laws and regulations that deter physicians from prescribing analgesia should be reexamined and alternative strategies employed, such as providing immunity from discipline for physicians who prescribe analgesic medications according to evidence-based guidelines, and education outlining the 
complexity of pain management among IDUs, which needs to be widely available to clinicians [4,48]. Currently, basic management principles and guidelines exist [11-14], but may be based on 'low-quality evidence' or 'anecdotal experience' [14], and may not be widely available to clinicians who care for IDU clients. Furthermore, pain and addiction specialists should be involved in acute and non-acute healthcare settings, and medical schools should train physicians to specialize in addiction medicine in order to effectively manage pain among this complex population.

Without novel efforts to improve pain management among drug users, there may be grave consequences that extend beyond the issue of untreated pain, such as: substance users' decreased confidence in the medical system and deepened distrust of health practitioners due to perceived stigma; decreased hope of rehabilitation in terms of the individual's addiction and physical wellbeing; and a likelihood of prolonged addiction as a means of coping with pain $[4,17]$. Conversely, the effective pain management of IDUs may contribute to increased quality of life, increased function and hope for rehabilitation, and increased likelihood of accessing health and addiction treatment in the future after positive experiences with healthcare practitioners $[1,3,4]$. Furthermore, patients with a history of substance use may self-discharge or avoid healthcare owing to undertreated pain, particularly in acute care settings $[4,15]$. Thus, appropriate pain management of IDUs may contribute to reduced healthcare costs by decreasing the number of patients who self-discharge against medical advice and are often hospitalized with more severe and complex problems requiring more intense, prolonged and overall more expensive care $[4,15]$.

In summary, a large proportion of IDUs participating in this study reported a history of selfmanaged pain. Factors independently and positively associated with self-managed pain included having been refused a prescription for pain medication and having ever been homeless. The most commonly reported methods of self-managing pain included injecting heroin and obtaining diverted prescription pain medication from the street. Our findings indicate the need for novel efforts to improve pain management among IDUs in order to offset the high-risk behaviors associated with self-managed pain.

\section{Acknowledgments}

The authors thank the VIDUS and ACCESS study participants for their contribution to the research, as well as current and past researchers and staff. They would specifically like to thank Tricia Collingham, Carmen Rock, Deborah Graham and Peter Vann for their assistance with this research. They also thank the members of the Vancouver Area Network of Drug Users (VANDU) for their assistance in developing the research question.

\section{References}

Papers of special note have been highlighted as:

- of interest

- of considerable interest

1-. Breitbart W, Rosenfeld B, Passik S, Kaim M, Funesti-Esch J, Stein K. A comparison of pain report and adequacy of analgesic therapy in ambulatory AIDS patients with and without a history of substance abuse. Pain. 1997; 72(1-2):235-243. Review of evidence for management of the hospitalized injection drug user. [PubMed: 9272808]

2. Haber PS, Demirkol A, Lange K, Murnion B. Management of injecting drug users admitted to hospital. Lancet. 2009; 374(9697):1284-1293. [PubMed: 19819393]

3. Pieper B, Templin T. Lower extremity changes, pain, and function in injection drug users. J Subst Abuse Treat. 2003; 25(2):91-97. [PubMed: 14629991] 
4-. Hopper JA, Shafi T. Management of the hospitalized injection drug user. Infect Dis Clin North Am. 2002; 16(3):571-587. Overview of issues and approaches in managing the hospitalized injection drug user. [PubMed: 12371116]

5. Pieper B, Szczepaniak K, Templin T. Psychosocial adjustment, coping, and quality of life in persons with venous ulcers and a history of intravenous drug use. J Wound Ostomy Continence Nurs. 2000; 27(4):227-237. [PubMed: 10896748]

6. Binswanger IA, Kral AH, Bluthenthal RN, Rybold DJ, Edlin BR. High prevalence of abscesses and cellulitis among community-recruited injection drug users in San Francisco. Clin Infect Dis. 2000; 30(3):579-581. [PubMed: 10722447]

7. Mathers BM, Degenhardt L, Phillips B, et al. Global epidemiology of injecting drug use and HIV among people who inject drugs: a systematic review. Lancet. 2008; 372(9651):1733-1745. [PubMed: 18817968]

8. Shepard CW, Finelli L, Alter MJ. Global epidemiology of hepatitis C virus infection. Lancet Infect Dis. 2005; 5(9):558-567. [PubMed: 16122679]

9. Pud D, Cohen D, Lawental E, Eisenberg E. Opioids and abnormal pain perception: new evidence from a study of chronic opioid addicts and healthy subjects. Drug Alcohol Depend. 2006; 82(3): 218-223. [PubMed: 16229972]

10. Berg KM, Arnsten JH, Sacajiu G, Karasz A. Providers' experiences treating chronic pain among opioid-dependent drug users. J Gen Intern Med. 2009; 24(4):482-488. [PubMed: 19189194]

11. Savage, SR. Section 12: pain and addiction. Chapter 2: principles of pain management in the addicted patient. In: Graham, AW.; Schultz, TK., editors. Principles of Addiction Medicine. 2. American Society of Addiction Medicine, MD; USA: 1998. p. 1405-1420.

12. Miotto K, Kaufman A, Kong A, Jun G, Schwartz J. Managing co-occurring substance use and pain disorders. Psychiatr Clin North Am. 2012; 35(2):393-409. [PubMed: 22640762]

13. Prater CD, Zylstra RG, Miller KE. Successful pain management for the recovering addicted patient. Prim Care Companion J Clin Psychiatry. 2002; 4(4):125-131. [PubMed: 15014719]

14. Chou R, Fanciullo GJ, Fine PG, et al. Clinical guidelines for the use of chronic opioid therapy in chronic noncancer pain. J Pain. 2009; 10(2):113-130. [PubMed: 19187889]

15. Baldacchino A, Gilchrist G, Fleming R, Bannister J. Guilty until proven innocent: a qualitative study of the management of chronic non-cancer pain among patients with a history of substance abuse. Addict Behav. 2010; 35(3):270-272. [PubMed: 19897313]

16. McCreaddie M, Lyons I, Watt D, et al. Routines and rituals: a grounded theory of the pain management of drug users in acute care settings. J Clin Nursing. 2010; 19(19-20):2730-2740.

17. Merrill JO, Rhodes LA, Deyo RA, Marlatt GA, Bradley KA. Mutual mistrust in the medical care of drug users: the keys to the 'narc' cabinet. J Gen Intern Med. 2002; 17(5):327-333. [PubMed: 12047728]

18. Tyndall MW, Currie S, Spittal P, et al. Intensive injection cocaine use as the primary risk factor in the Vancouver HIV-1 epidemic. Aids. 2003; 17(6):887-893. [PubMed: 12660536]

19. Wood E, Hogg RS, Lima VD, et al. Highly active antiretroviral therapy and survival in HIVinfected injection drug users. JAMA. 2008; 300(5):550-554. [PubMed: 18677027]

20. Wood E, Tyndall MW, Spittal PM, et al. Unsafe injection practices in a cohort of injection drug users in Vancouver: could safer injecting rooms help? CMAJ. 2001; 165(4):405-410. [PubMed: 11531048]

21. Obradovic M, Lal A, Liedgens H. Validity and responsiveness of EuroQol-5 dimension (EQ-5D) versus Short Form-6 dimension (SF-6D) questionnaire in chronic pain. Health Qual Life Outcomes. 2013; 11:110. [PubMed: 23815777]

22. Van Der Zanden BP, Dijkgraaf MG, Blanken P, De Borgie CA, Van Ree JM, Van Den Brink W. Validity of the EQ-5D as a generic health outcome instrument in a heroin-dependent population. Drug Alcohol Depend. 2006; 82(2):111-118. [PubMed: 16168573]

23. Hurst NP, Kind P, Ruta D, Hunter M, Stubbings A. Measuring health-related quality of life in rheumatoid arthritis: validity, responsiveness and reliability of EuroQol (EQ-5D). Br J Rheumatol. 1997; 36(5):551-559. [PubMed: 9189057]

24. Centers for Disease Control and Prevention. Indicators for chronic disease surveillance. MMWR. 2004; 53:19-27. 
25. National Institute of Alcohol Abuse and Alcoholism (NIAAA). NIAAA council approves definition of binge drinking. NIAAA Newsletter. 2004; 3:3.

26. United States Department of Agriculture and United States Department of Health and Human Services. Dietary Guidelines for Americans. US Government Printing Office; Washington, DC, USA: 2005. Chapter 9. Alcoholic beverages; p. 43-66.

27. Substance Abuse and Mental Health Services Administration. Results from the 2009 National Survey on Drug Use and Health: Volume I. Summary of National Findings. Office of Applied Studies; USA: 2010. NSDUH Series H-38A, HHS Publication No. SMA 10-4586 Findings, MD

28. Craib KJ, Spittal PM, Wood E, et al. Risk factors for elevated HIV incidence among Aboriginal injection drug users in Vancouver. CMAJ. 2003; 168(1):19-24. [PubMed: 12515780]

29. Wood E, Tyndall MW, Spittal PM, et al. Factors associated with persistent high-risk syringe sharing in the presence of an established needle exchange programme. AIDS. 2002; 16(6):941943. [PubMed: 11919503]

30. Catalano J. Pain management and substance abuse: a national dilemma. Soc Work Public Health. 2009; 24(6):477-490. [PubMed: 19821188]

31. Krashin D, Murinova N, Ballantyne J. Management of pain with comorbid substance abuse. Curr Psychiatry Rep. 2012; 14(5):462-468. [PubMed: 22843539]

32. Jamison RN, Kauffman J, Katz NP. Characteristics of methadone maintenance patients with chronic pain. J Pain Symptom Manage. 2000; 19(1):53-62. [PubMed: 10687327]

33. Stanos SP, Bruckenthal P, Barkin RL. Strategies to reduce the tampering and subsequent abuse of long-acting opioids: potential risks and benefits of formulations with physical or pharmacologic deterrents to tampering. Mayo Clin Proc. 2012; 87(7):683-694. [PubMed: 22766088]

34. Wiedemer NL, Harden PS, Arndt IO, Gallagher RM. The opioid renewal clinic: a primary care, managed approach to opioid therapy in chronic pain patients at risk for substance abuse. Pain Med. 2007; 8(7):573-584. [PubMed: 17883742]

35. Manheimer E, Anderson BJ, Stein MD. Use and assessment of complementary and alternative therapies by intravenous drug users. Am J Drug Alcohol Abuse. 2003; 29(2):401-413. [PubMed: 12765213]

36. Alford, DP.; Waldmann, CA. Pain management. In: O'Connell, JJ., editor. The Health Care of Homeless Persons: A Manual of Communicable Diseases \& Common Problems in Shelters \& on the Streets. Boston Health Care for the Homeless Program; MA, USA: 2004. p. 227-235.

37. Matter R, Kline S, Cook KF, Amtmann D. Measuring pain in the context of homelessness. Qual Life Res. 2009; 18(7):863-872. [PubMed: 19582592]

38. Hwang SW, Wilkins E, Chambers C, Estrabillo E, Berends J, Macdonald A. Chronic pain among homeless persons: characteristics, treatment, and barriers to management. BMC Fam Pract. 2011; 12:73. [PubMed: 21740567]

39. Turnbull J, Muckle W, Masters C. Homelessness and health. CMAJ. 2007; 177(9):1065-1066. [PubMed: 17954899]

40. Darke S, Hall W. Heroin overdose: research and evidence-based intervention. J Urban Health. 2003; 80(2):189-200. [PubMed: 12791795]

41. Nelson PK, Mathers BM, Cowie B, et al. Global epidemiology of hepatitis B and hepatitis C in people who inject drugs: results of systematic reviews. Lancet. 2011; 378(9791):571-583. [PubMed: 21802134]

42. Phillips KT, Stein MD. Risk practices associated with bacterial infections among injection drug users in Denver, Colorado. Am J Drug Alcohol Abuse. 2010; 36(2):92-97. [PubMed: 20337504]

43. Khosla N, Juon HS, Kirk GD, Astemborski J, Mehta SH. Correlates of non-medical prescription drug use among a cohort of injection drug users in Baltimore City. Addict Behav. 2011; 36(12): 1282-1287. [PubMed: 21868170]

44. Monga N, Rehm J, Fischer B, et al. Using latent class analysis (LCA) to analyze patterns of drug use in a population of illegal opioid users. Drug Alcohol Depend. 2007; 88(1):1-8. [PubMed: 17049753]

45. Davis WR, Johnson BD. Prescription opioid use, misuse, and diversion among street drug users in New York City. Drug Alcohol Depend. 2008; 92(1-3):267-276. [PubMed: 17913395] 
46. Inciardi JA, Surratt HL, Cicero TJ, Beard RA. Prescription opioid abuse and diversion in an urban community: the results of an ultrarapid assessment. Pain Med. 2009; 10(3):537-548. [PubMed: 19416440]

47. Rigg KK, Kurtz SP, Surratt HL. Patterns of prescription medication diversion among drug dealers. Drugs. 2012; 19(2):144-155. [PubMed: 22665955]

48-. Manchikanti L. Prescription drug abuse: what is being done to address this new drug epidemic? Testimony before the Subcommittee on Criminal Justice, Drug Policy and Human Resources. Pain Physician. 2006; 9(4):287-321. Comprehensive health policy review of prescription drug abuse in the USA, including the issue of drug diversion. [PubMed: 17066115]

\section{Website}

101. International Association for the Study of Pain taxonomy: pain terms. [Accessed 5 August 2013] www.iasp-pain.org/Content/NavigationMenu/GeneralResourceLinks/PainDefinitions/default.htm 


\section{Practice Points}

- People who inject drugs (IDUs) often contend with short-term and chronic pain due to various comorbidities. Clinicians may be reluctant to prescribe pain medications owing to concerns about drug-seeking by IDUs.

- As a result, some IDUs may resort to self-management of pain, although this phenomenon has received little attention.

- The Vancouver Injection Drug Users Study (VIDUS) and the AIDS Care Cohort to Evaluate Access to Survival Services (ACCESS) are two prospective cohort studies of IDUs in Vancouver (Canada).

- Among participants enrolled in VIDUS and ACCESS, we used logistic regression analysis to evaluate factors associated with self-management of pain. We also examined self-reported methods of pain management.

- Four hundred and eighty three IDUs who reported moderate-to-extreme pain were eligible for this analysis, of which $160(33.1 \%)$ were female. Two hundred and twenty four $(46.4 \%)$ were HIV positive. The median age was 49.6 years (interquartile range: 43.9-54.6 years).

- Self-management of pain was common among IDUs in this cohort, with 471 IDUs $(97.5 \%)$ reporting self-management of pain.

- Variables independently and positively associated with self-managed pain included having been refused a prescription for pain medication, and having ever been homeless.

- Common methods of self-management of pain included injecting heroin $(52.7 \%)$ and obtaining diverted prescription pain medication from the street $(65.0 \%)$.

- $\quad$ Novel efforts to improve pain management for IDUs are necessary. These may include clinical guidelines for pain management among IDUs and involving pain and addiction specialists in healthcare settings.

- Improved pain management for IDUs in the clinical setting may serve to reduce the prevalence of self-management of pain in ways that pose high risk for morbidity and mortality. 
Table 1

Bivariate analysis of factors associated with self-management of pain among people who inject drugs in Vancouver (Canada) reporting moderate-to-extreme pain $(n=483)$.

\begin{tabular}{|c|c|c|c|c|}
\hline \multirow[t]{2}{*}{ Characteristic } & \multicolumn{2}{|c|}{ Self-managed pain ${ }^{\dagger}$} & \multirow[t]{2}{*}{ Unadjusted odds ratio $(95 \% \mathrm{CI})$} & \multirow[t]{2}{*}{ p-value } \\
\hline & Yes: $471(97.5 \%)$ & No: $12(2.5 \%)$ & & \\
\hline \multicolumn{5}{|l|}{ Age } \\
\hline$>$ Median & $236(48.9)$ & $5(1.0)$ & $1.41(0.44-4.49)$ & 0.565 \\
\hline Median & $235(48.7)$ & $7(1.5)$ & & \\
\hline \multicolumn{5}{|l|}{ Gender } \\
\hline Male & $312(65.6)$ & $11(2.3)$ & $0.18(0.02-1.39)$ & 0.100 \\
\hline Female & $159(32.9)$ & $1(0.2)$ & & \\
\hline \multicolumn{5}{|l|}{ Homelessness $^{\dagger}$} \\
\hline Yes & $423(87.6)$ & $8(1.7)$ & $4.41(1.28-15.2)$ & 0.019 \\
\hline No & $48(9.9)$ & $4(0.8)$ & & \\
\hline \multicolumn{5}{|c|}{ Unstable housing ${ }^{t}$} \\
\hline Yes & $281(60.8)$ & $4(0.9)$ & $2.89(0.83-10.0)$ & 0.094 \\
\hline No & $170(36.8)$ & $7(1.5)$ & & \\
\hline \multicolumn{5}{|c|}{ DTES residence ${ }^{f}$} \\
\hline Yes & $284(58.8)$ & $4(0.8)$ & $3.04(0.90-10.2)$ & 0.073 \\
\hline No & $187(38.7)$ & $8(1.7)$ & & \\
\hline \multicolumn{5}{|c|}{ Education status ${ }^{\S}$} \\
\hline High school & $241(51.4)$ & $7(1.5)$ & $0.80(0.25-2.55)$ & 0.702 \\
\hline$<$ High school & $216(46.1)$ & $5(1.1)$ & & \\
\hline \multicolumn{5}{|l|}{ HIV status } \\
\hline Positive & $221(45.8)$ & $3(0.6)$ & $2.65(0.71-9.92)$ & 0.147 \\
\hline Negative & $250(51.8)$ & $9(1.9)$ & & \\
\hline \multicolumn{5}{|l|}{ Sex work $^{\dagger}$} \\
\hline Yes & $257(53.2)$ & $8(1.7)$ & $0.60(0.18-2.02)$ & 0.410 \\
\hline No & $214(44.3)$ & $4(0.8)$ & & \\
\hline \multicolumn{5}{|l|}{ Incarceration $\neq \S$} \\
\hline Yes & $23(4.8)$ & $1(0.2)$ & $0.57(0.07-4.57)$ & 0.593 \\
\hline No & 447 (92.7) & $11(2.3)$ & & \\
\hline
\end{tabular}




\begin{tabular}{|c|c|c|c|c|}
\hline \multirow[t]{2}{*}{ Characteristic } & \multicolumn{2}{|c|}{ Self-managed pain ${ }^{\dagger}$} & \multirow[t]{2}{*}{ Unadjusted odds ratio (95\% CI) } & \multirow[t]{2}{*}{ p-value } \\
\hline & Yes: $471(97.5 \%)$ & No: $12(2.5 \%)$ & & \\
\hline \multicolumn{5}{|c|}{ Physical disabilities ${ }^{\dagger}$} \\
\hline Yes & $307(63.6)$ & $5(1.0)$ & $2.62(0.82-8.39)$ & 0.105 \\
\hline No & $164(34.0)$ & $7(1.5)$ & & \\
\hline \multicolumn{5}{|c|}{ Refused pain medication ${ }^{\dagger}$} \\
\hline Yes & $294(60.9)$ & $2(0.4)$ & $8.31(1.80-38.3)$ & 0.007 \\
\hline No & $177(36.7)$ & $10(2.1)$ & & \\
\hline \multicolumn{5}{|l|}{ Ever. } \\
\hline
\end{tabular}

DTES: Downtown Eastside. 
Table 2

Bivariate analysis of drug use-related factors associated with self-management of pain among people who inject drugs in Vancouver (Canada) reporting moderate-to-extreme pain $(n=483)$.

\begin{tabular}{|c|c|c|c|c|}
\hline \multirow[t]{2}{*}{ Characteristic } & \multicolumn{2}{|c|}{ Self-managed pain ${ }^{\dagger}$} & \multirow[t]{2}{*}{ Unadjusted odds ratio (95\% CI) } & \multirow[t]{2}{*}{ p-value } \\
\hline & Yes: $471(97.5 \%)$ & No: $12(2.5 \%)$ & & \\
\hline \multicolumn{5}{|c|}{ Daily noninjection crack use $\mathrm{f}^{\ddagger} \S$} \\
\hline Yes & $85(17.7)$ & $2(0.4)$ & $1.11(0.24-5.16)$ & 0.894 \\
\hline No & $383(79.8)$ & $10(2.1)$ & & \\
\hline \multicolumn{5}{|c|}{ Daily crystal meth injection $\$$} \\
\hline Yes & $25(5.2)$ & $1(0.2)$ & $0.62(0.08-4.98)$ & 0.651 \\
\hline No & $445(92.3)$ & $11(2.3)$ & & \\
\hline \multicolumn{5}{|c|}{ Daily heroin injection $\$$} \\
\hline Yes & $58(12.0)$ & $1(0.2)$ & $1.55(0.20-12.2)$ & 0.678 \\
\hline No & $412(85.5)$ & $11(2.3)$ & & \\
\hline \multicolumn{5}{|c|}{ Daily cocaine injection $\$ \S$} \\
\hline Yes & $30(6.24)$ & $1(0.2)$ & $0.75(0.09-6.01)$ & 0.788 \\
\hline No & $439(91.3)$ & $11(2.3)$ & & \\
\hline \multicolumn{5}{|c|}{ 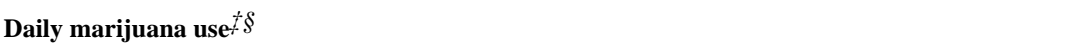 } \\
\hline Yes & $103(21.5)$ & $2(0.4)$ & $1.42(0.31-6.56)$ & 0.197 \\
\hline No & $364(76.0)$ & $10(2.1)$ & & \\
\hline \multicolumn{5}{|c|}{ Heavy alcohol use ${ }^{\ddagger}$} \\
\hline Yes & $93(19.3)$ & $1(0.2)$ & $2.71(0.35-21.2)$ & 0.344 \\
\hline No & $378(78.3)$ & $11(2.3)$ & & \\
\hline \multicolumn{5}{|c|}{ Prescription opioid abuse ${ }^{\ddagger}$} \\
\hline Yes & $95(19.8)$ & $1(0.2)$ & $2.79(0.36-21.9)$ & 0.328 \\
\hline No & $374(77.8)$ & $11(2.3)$ & & \\
\hline \multicolumn{5}{|c|}{ Enrolled in $\mathbf{M M T}^{\dagger}$} \\
\hline Yes & $337(69.8)$ & $6(1.24)$ & $2.52(0.80-7.94)$ & 0.116 \\
\hline No & $134(27.7)$ & $6(1.24)$ & & \\
\hline \multicolumn{5}{|l|}{ Overdose $^{\dagger}$} \\
\hline Yes & $304(62.9)$ & $7(1.5)$ & $1.30(0.41-4.16)$ & 0.658 \\
\hline No & 167 (34.6) & $5(1.0)$ & & \\
\hline
\end{tabular}

Pain Manag. Author manuscript; available in PMC 2014 November 01. 


\begin{tabular}{|c|c|c|c|c|}
\hline \multirow[t]{2}{*}{ Characteristic } & \multicolumn{2}{|c|}{ Self-managed pain ${ }^{\dagger}$} & \multirow[t]{2}{*}{ Unadjusted odds ratio (95\% CI) } & \multirow[t]{2}{*}{ p-value } \\
\hline & Yes: $471(97.5 \%)$ & No: $12(2.5 \%)$ & & \\
\hline \multicolumn{5}{|c|}{ Binge injection drug use $\$ \xi$} \\
\hline Yes & $94(19.5)$ & $2(0.4)$ & $1.25(0.27-5.80)$ & 0.776 \\
\hline No & $376(78.0)$ & $10(2.1)$ & & \\
\hline \multicolumn{5}{|l|}{ Ever. } \\
\hline \multicolumn{5}{|c|}{ Within the last 6 months (at time of interview). } \\
\hline
\end{tabular}

MMT: Methadone maintenance treatment. 
Table 3

Logistic regression analysis of factors associated with self-management of pain among people who inject drugs in Vancouver (Canada) reporting moderate-to-extreme pain $(n=483)$.

\begin{tabular}{|c|c|c|c|}
\hline Variable & Adjusted odds ratio & $95 \% \mathrm{CI}$ & p-value \\
\hline \multicolumn{4}{|c|}{ Refused pain medication $^{\dagger}$} \\
\hline Yes vs no & 7.83 & $1.64-37.3$ & 0.010 \\
\hline \multicolumn{4}{|l|}{ Homelessness ${ }^{\dagger}$} \\
\hline Yes vs no & 3.70 & $1.00-13.7$ & 0.050 \\
\hline \multicolumn{4}{|l|}{ Gender } \\
\hline Male vs female & 0.17 & $0.02-1.39$ & 0.098 \\
\hline
\end{tabular}


Table 4

Self-reported ${ }^{\dagger}$ methods of self-management of pain among people who inject drugs in Vancouver (Canada) reporting moderate-to-extreme pain and self-managed pain $(n=471)$.

\begin{tabular}{|c|c|}
\hline Method & $\mathrm{n}(\%), \mathrm{n}=\mathbf{4 7 1 ^ { \dagger }}$ \\
\hline Inject heroin & $248(52.7)$ \\
\hline Smoke/snort heroin & $40(8.5)$ \\
\hline Obtained prescription pain medication from the street: & $306(65.0)$ \\
\hline - Morphine & $204(43.3)$ \\
\hline - Hydromorphone (e.g., Dilaudid ${ }^{\circledR}$, Purdue Pharma, Ontario, Canada) & $150(31.8)$ \\
\hline - Acetaminophen with codeine (e.g., Tylenol ${ }^{\circledR}$ with Codeine \#3, McNeil Consumer Healthcare, Ontario, Canada) & $119(25.3)$ \\
\hline - Acetaminophen with oxycodone (e.g., Percocet ${ }^{\circledR}$, Bristol-Myers Squibb Canada, Quebec, Canada) & $65(13.8)$ \\
\hline Obtained prescription pain medication from a friend/partner/acquaintance: & $118(25.1)$ \\
\hline - Morphine & $51(10.8)$ \\
\hline - Acetaminophen with codeine (e.g., Tylenol with Codeine \#3) & $49(10.4)$ \\
\hline - Hydromorphone (e.g., Dilaudid) & $35(16.4)$ \\
\hline - Acetaminophen with oxycodone (e.g., Percocet) & $17(7.9)$ \\
\hline \multicolumn{2}{|l|}{ Other drug use: } \\
\hline - Marijuana & $101(21.4)$ \\
\hline - Cocaine & $43(9.1)$ \\
\hline - Crack & $41(8.7)$ \\
\hline - Alcohol & $37(7.9)$ \\
\hline \multicolumn{2}{|l|}{ Over-the-counter medication: } \\
\hline - Ibuprofen (e.g., Advil ${ }^{\circledR}$, Pfizer Canada, Quebec, Canada) & $60(12.7)$ \\
\hline - Acetaminophen (e.g., Regular Strength Tylenol) & $42(8.9)$ \\
\hline Nothing/ignore it/suffer through it/wait for it to pass & $96(20.4)$ \\
\hline Heat (e.g., hot bath/shower, hot compress/pad) & $48(10.2)$ \\
\hline Exercise & $39(8.3)$ \\
\hline Rest/relax/relaxation techniques & $38(8.1)$ \\
\hline
\end{tabular}

${ }^{\dagger}$ Participants were able to provide more than one answer. 